\title{
ONTOLOGÍA Y CIENCIA: DE LA SUBSTANCIA ARISTOTÉLICA A LA SUSTANTIVIDAD ZUBIRIANA
}

\section{Carlos Sierra-Lechuga*}

En este artículo presentaré la tesis de que la ciencia ha continuado pensando aristotélicamente en función del concepto de sustancia y propondré otra variable independiente: la sustantividad. Para ello, echaré mano brevemente de los horizontes de comprensión que Xavier Zubiri ha encontrado en Occidente (movilidad y nihilidad), para luego mostrar por qué nuestra situación intelectual nos invita a pensar en las estructuras de las cosas desde un horizonte que podría llamarse de la complejidad.

Palabras clave: estructura, complejidad, sistema, horizontes de comprensión, Zubiri.

ONTOLOGY AND SCIENCE: FROM ARISTOTELIAN SUBSTANCE TO ZUBIRIAN SUBSTANTIVITY

In this paper I will present the thesis that science has continued thinking in an Aristotelian way in terms of the concept of substance, and I will propose another independent variable: substantivity. To do this, I will briefly talk about on the horizons of understanding that X. Zubiri found in West (mobility and nihility) and, then, I will show why our intellectual situation invites us to think of structures of the things from a horizon that could be called of complexity.

Keywords: structure, complexity, system, horizons of understanding, Zubiri.

\footnotetext{
* Academia Internacional Tomás de Aquino (AITA). Correo electrónico: rideo_ergo_sum@hotmail.com.*
} 


\section{Introducción}

LA CIENCIA, EN NUESTROS TIEMPOS Y DESDE HACE MÁs DE cien años, ha lanzado nuevos modos de acercamiento a la realidad física y, con ello, nuevos retos que desafían dichos modos; trayendo con ello la necesidad de nuevos horizontes de comprensión. Problemas clásicos como el principio de mínima acción, la diferencia física entre masa gravitacional e inercial; y contemporáneos como la antes llamada "dualidad onda-partícula", la delgada línea entre el observador y lo observado tanto experimentalmente -el Efecto Compton, por ejemplo- como teóricamente -el principio de indeterminación de Heisenberg-, el problema de integrar la fuerza gravitacional al modelo estándar, la barrera infranqueable de la velocidad límite de transmisión de información, la existencia de un bosón constitutivo en la formación de la materia, la ondas gravitacionales, el problema de la evolución y sus múltiples teorías, los organismos vivos, la autoorganización de la materia, el enlazamiento cuántico, la emergencia de la inteligencia, el paso entre una macromolécula a una célula, el espacio-tiempo, entre muchos más. En fin, el propio concepto de sistema da cuenta clara de una situación intelectual que requiere de la especulación filosófica para clarificar los fundamentos de nuestros modos de acercamiento a la realidad material.

Si existen problemas en la ciencia de orden epistemológico u ontológico, es decir, si en ella existen problemas meta-científicos, se debe en parte -creemos-al horizonte de precomprensiones desde el cual se les está enfrentando; esto es, a la clave de interpretación. En este artículo presentaré la tesis de que la ciencia ha continuado pensando aristotélicamente en función del concepto de sustancia y que ha sido por ello que ciertos acercamientos a nuevos fenómenos resultan improcedentes o enclenques; en virtud de esto propondré otra variable independiente: la noción de sustantividad del filósofo Xavier Zubiri, que considero más urgente y apropiada en la situación intelectual de nuestros tiempos. Para ello, echaré mano brevemente de los horizontes de comprensión que el mismo Zubiri ha encontrado en la historia del pensamiento occidental, mostrando cómo los horizontes previos al nuestro piensan según la sustancia aristotélica, para luego mostrar por qué nuestra situación intelectual nos invita a pensar en las estructuras complejas desde un nuevo horizonte -al menos de cara a las ciencias físicas. Concluiré mostrando que para nuestro horizonte se requiere pensar no tanto en términos de substancia cuanto de sustantitividad si como filósofos queremos estar a la "altura de nuestros tiempos". 
Para empezar, sin embargo, aclaro que por "ontología" no entiendo una ontología clásica, es decir, no entiendo por ella "el conocimiento del ser expresado en logos", sino, ante todo, una disciplina filosófica que estudia lo real en tanto que real (diferenciada de la metafísica, por estudiar ésta la realidad qua realidad); entiendo entonces por tò òv lo estante, y no "el ente" clásico. Por otro lado, es preciso notar que en las lecturas de raigambre fenomenológica que Zubiri hizo del pensamiento aristotélico, encontró que Aristóteles se refiere con ov̉oía a dos cosas diferentes en virtud del modo como uno accede a ella, a

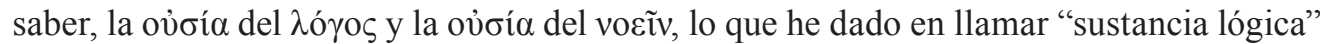
y "sustancia noética"; aclaro, pues, que por sustancia me refiero a la primera, pues a la segunda el Zubiri maduro llamaría sustantividad".

Vayamos, pues, a pasos contados: ¿qué es sustancia aristotélica?, ¿qué es sustantividad zubiriana?, ¿cuáles son los horizontes desde los que se piensa occidentalmente y es acaso verdad que en ellos la sustancia tipifica cómo conocer el mundo?, ¿cuál es nuestro horizonte y puede la sustantividad auxiliarnos en nuevos modos de conocer?, y finalmente, ¿qué concluimos de todo esto?

\section{Sustancia aristotélica}

Preciso que hablaré de sustancia aristotélica y no de "sustancia en Aristóteles" a pesar de que mi referencia primera a ella sean los propios textos de aquél filósofo. Esta precisión en el fondo apunta a que la lectura que hago de la sustancia aristotélica sí es la lectura clásica, es decir, la lectura que sus intérpretes en la tradición general han hecho, y no así la lectura que hoy los grandes estudiosos del pensamiento clásico griego pudieran encontrar novedosa. Me apego a esa lectura clásica porque la historia en general así lo ha hecho, y aquí me interesa qué ha pensado la historia. Esta interpretación tradicional ha versado siempre en torno a la "sustancia lógica", y a ésta me referiré. Dicho esto, ¿qué es sustancia?

La sustancia está presente en todo el discurso que forjó al pensamiento moderno y, con ello, a su ciencia. Grosso modo, lo que llamamos sustancia es lo que en griego se dijo ov̉ $\sigma \alpha^{2} \alpha^{2}$, de oṽ $\sigma \alpha$, participio presente femenino del verbo év $\alpha \alpha$, ser -o como yo preferiría: estar. Lo estante ( $\tau$ ò òv) se dice siempre de un único principio: la sustancia ${ }^{3}$. Aristóteles ha

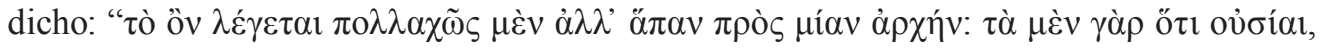

1 Cfr. Zubiri, X., "Filosofía y Metafísica", Cruz y Raya 10, 1935, pp. 7-60. También: Zubiri, X., Los problemas fundamentales de la metafísica occidental, Alianza, Madrid, 2008, pp. 67-68. En esta última referencia, Zubiri

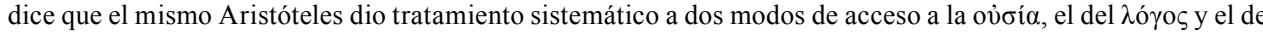

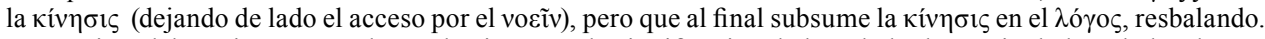

2 La propia palabra ov̉oía es usada en el griego con la significación de heredad o herencia; la heredad es lo que garantiza la independencia de algo (cuando un joven hereda, es independiente de su familia y demás trabajos). De aquí que se usara esta misma palabra, pero compuesta, para indicar "autoridad": $\dot{\varepsilon} \xi o v \sigma i ́ \alpha$. Todavía hoy, en griego moderno, se habla de los bienes y la fortuna como $\pi \varepsilon \rho \iota 0 v \sigma i ́ \alpha$.

3 Quizá haya mejores traducciones para ov̉oía, pero la tradicional ha sido sustancia. Aunque estrictamente esté en desacuerdo con llamarle así, prefiero dejarla tal y como se le ha llamado para señalar la tradición de este horizonte. 


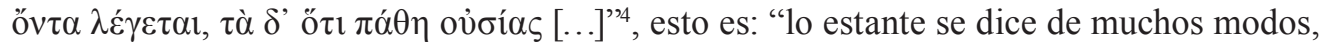
pero en todos ellos de cara a (respecto de) un único principio: pues de unas cosas se dice

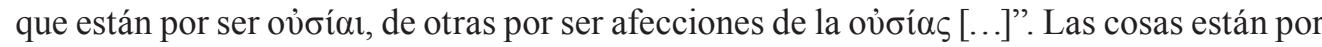
ser sustanciales, y aquello que no es sustancial depende de aquello que sí lo es. Es claro, pues lo estante está fundamentalmente debido a aquello que lo hace estar, que es independiente de todo lo demás por ser precisamente ello lo más estante. Lo que los griegos $-\mathrm{y}$ luego los escolásticos- entendieron por sustancia es lo que está-ahí, el ahí del estar, subsistiendo bajo otras realidades; la sustancia es, en esta medida, una realidad no dependiente

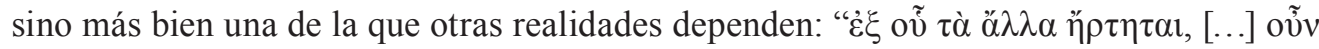

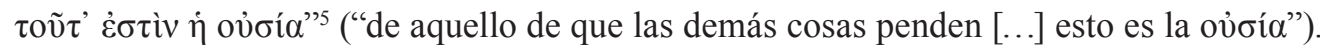

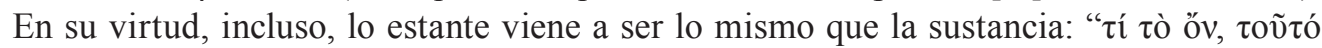

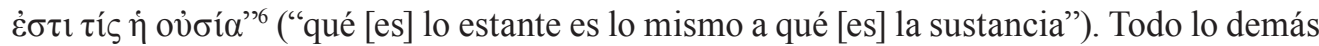
o no está, o lo está sólo por estar en lo más estante. Este en refiere en todo caso a un con, hay cosas que sólo están por estar con lo más estante, por acompañarlo. Esta es la clásica

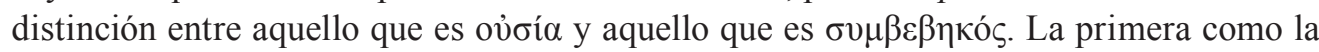
realidad primordial propia de sí misma, la segunda como lo que acompaña a la realidad primaria, como lo que siendo con la ov̉oía podría ser, sin embargo, de otra manera, es decir, como su accidente (accidens); lo $\sigma 0 \mu-\beta \varepsilon \beta \eta \kappa o ́ \varsigma$ es "lo-ido-con" la sustancia.

De este modo, traída la ov̉øía a terrenos epistemológicos, se dice que la sustancia es la realidad primaria y, como tal, conociendo su realidad tendremos un conocimiento completo de la realidad propia de la cosa misma. Decía Tomás de Aquino que hay un principio (principium) en las cosas (re) según el cual -y sólo gracias a él- podrá conocérseles (sit modus eorum quae de re illa cognoscuntur); es decir que conociendo la sustancia de la cosa (rei substantiam) nada de la cosa inteligida excederá la razón humana (nullum intelligibilium illius rei facultatem humanae rationis excedet) ${ }^{7}$. Esto será preclaro para lo que

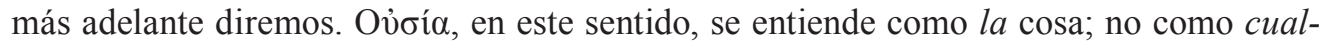
quier cosa. Es la cosa más cosa, es la cosa presente, más presente, según la cual el resto de la cosa queda precisamente delimitada ( $\pi \dot{\varepsilon} \rho \alpha \varsigma)$ como cosa.

4 Aristóteles, Met. 1003b5. Aristotle's Metaphysics, trad. de W.D. Ross, Clarendon Press, Oxford, 1924. Todas las citas griegas que vienen de la Metafísica se tomarán de esta edición. Las traducciones al castellano de las mismas son mías, permitiéndome dejar en griego los términos que considero clave.

5 ARistóteles, Met. $1003 \mathrm{~b} 18$.

6 ARistóteles Met. $1028 \mathrm{~b} 3$.

7 De Aquino, Tomás, SCG I, 3: “Cum enim principium totius scientiae quam de aliqua re ratio percipit, sit intellectus substantiae ipsius, eo quod, secundum doctrinam Philosophi, demonstrationis principium est quod quid est; oportet quod secundum modum quo substantia rei intelligitur, sit modus eorum quae de re illa cognoscuntur. Unde si intellectus humanus alicuius rei substantiam comprehendit, puta lapidis vel trianguli, nullum intelligibilium illius rei facultatem humanae rationis excedet." Summa contra gentiles, Typis Ricardi Garroni, Romae, 1928, pp. 7-8. /"El principio del que parte toda ciencia que pueda la razón percibir acerca de alguna cosa, es la captación de la sustancia de la misma: porque como dice el Filósofo, el principio de toda demostración es la esencia (aquello que es) de una cosa. Y así, según el modo como se intelige la sustancia de una cosa, así es como la cosa ella es conocida. Por ello, si la inteligencia humana puede comprender la sustancia de alguna cosa, como de una piedra o de un triángulo, nada excede la inteligibilidad de esa cosa a la facultad de la razón humana". De Aquino, Tomás, Suma contra los gentiles, trad. de Carlos Ignacio González, Porrúa, México, 2004, p. 3. La cursivas han sido modificaciones mías a la traducción. 


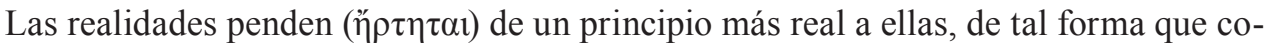
nociéndolo a éste conoceremos a aquéllas. No se trata de una extrapolación de dicho principio hacia la totalidad de la cosa, sino de la representación de la totalidad de la cosa en la presentación de dicho principio. Es en este sentido como la sustancia fue un concepto que marcó la historia de Occidente desde que Aristóteles la acuñó explícitamente ${ }^{8}$, tratándose, en efecto, de ella como algo $\pi \varepsilon ́ p \alpha \varsigma$ (delimitado), algo también $\kappa \alpha \theta^{\prime} \alpha v \tau o ́$ (suficiente) y algo

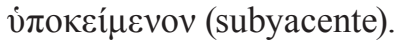

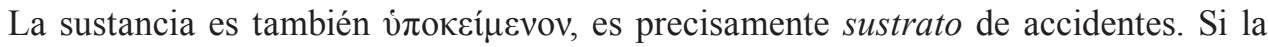
substancia es lo que está-ahí entonces es lo yaciente ( $\kappa \varepsilon i ̃ \alpha \imath)$, y estando además por debajo

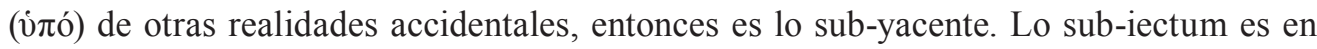
esa medida una realidad no dependiente; y así, lo substante deviene sub-yacente (vं

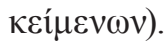

Pero la ciencia moderna es, precisamente, moderna, no griega ni medieval. ¿Qué hay con este principio substancial y subsistente según el cual conociéndolo a él se conoce a

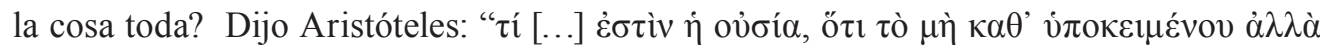

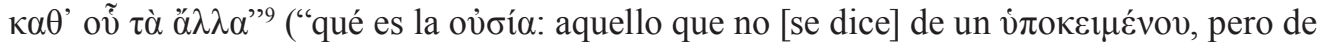
ello [se dicen] las demás [cosas]"). Pasa que, siendo la sustancia aquello que no se predica sino de lo cual se predica, en la Modernidad ocurrirá un giro en el que las sustancias se distinguen de lo que propiamente -a partir de entonces- llamamos sujeto. El sujeto es el conocedor de, o al menos quien intenta conocer, sustancias. Modernamente, la sustancia puede ser tanto cósica (por ejemplo, en el caso de Newton [substantia]) como "subjetiva" (la res cogitans de Descartes) e, incluso, exclusiva de la divinidad (como en su caso lo pensó Spinoza [substantia]). La oủoía griega termina desembocando medievalmente en conceptos substanciales como el de ens, del cual uno de sus trascendentales era ser quid (quiditas), lo que compartía cierta sinonimia con la afamada res. A partir de la Modernidad, la sustancia subjetiva (p.e. res cogitans) tenderá a buscar sustancias objetivas (p.e. res extensa) precisamente por estar puestas en frente, en $s u$ frente (Descartes, Leibniz) o, en su búsqueda, afirmará la imposibilidad de conocerlas (Locke, Hume, Kant) -es lo que se llamó ob-iectum: objeto. Quiero destacar este punto clave de la Modernidad: la sustancia subjetiva busca en las cosas sus sustancias (las sustancias objetivas), no sus accidentes. Busca de ellas lo que es más real -o lo que así se considera que sea más real-, no aquello que parece (frente al sujeto) no más que algo accidental (distinción típicamente moderna entre el ser y el parecer, esse y percipere). Por ello es que, bien entendido, Galileo -padre de la cinemática moderna- muestra esto diciendo:

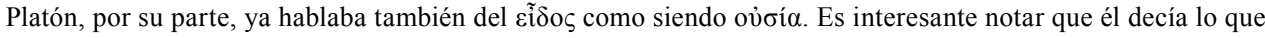
más abajo señalaremos decisivo en la interpretación zubiriana de la sustancia aristotélica y que sugeríamos al

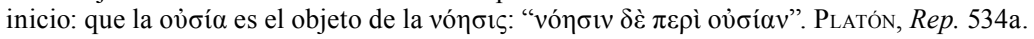

ARISTÓTELES, Met. 1029a8. 
[...] io dico che ben sento tirarmi dalla necessità, subito che concepisco una materia o sostanza corporea, a concepire insieme ch'ella è terminata e figurata di questa o di quella figura, ch'ella in relazione ad altre è grande o piccola, ch'ella è in questo o quel luogo, in questo o quel tempo, ch'ella si muove o sta ferma, ch'ella tocca o non tocca un altro corpo, ch'ella è una, poche o molte, né per veruna imaginazione posso separarla da queste condizioni; ma ch'ella debba essere bianca o rossa, amara o dolce, sonora o muta, di grato o ingrato odore, non sento farmi forza alla mente di doverla apprendere da cotali condizioni necessariamente accompagnata $[\ldots]^{10}$.

En tal pensamiento galileano se precomprende algo más real y algo que no lo es tanto, su acompañante nada más, esto es: sustancia y accidente. Incluso, inmediatamente después, el mismo Galileo nos habla precisamente de un sujeto (suggetto) en el que residen (riseggano) accidentes (accidenti). Nótese, por otro lado, que aquello de que uno tiene necesidad de concebir (necessità a concepire) junto con la sostanza apunta hacia lo

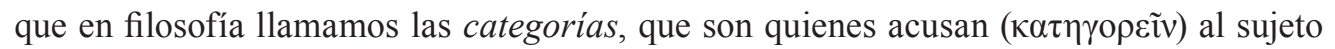
( metafísica clásica -lo que es preciso no olvidar so riesgo de resbalar en ideologías. Cuando el moderno quiere saber la sustancia de la cosa, abstrae todo cuanto la hace esa cosa, a excepción de su realidad primaria (o mejor dicho de lo que cree-precomprende-que es su realidad primaria), creyendo que todo lo demás cuanto la hace esa cosa es mero accidente.

\section{Sustantividad zubiriana}

Xavier Zubiri indicó que la filosofía en nuestros tiempos requiere de una metafísica de la sustantividad y no sólo de la sustancialidad. ¿Qué es la sustantividad?: "a la estructura radical de toda realidad [...] he llamado sustantividad" ". La sustantividad tiene, ante todo, una primaria "cualidad": ser-esta-cosa-presente. La sustantividad es algo delimitado y formal, diríamos acaso estructural y sistemático.

A mi modo de ver, las cosas están formalmente constituidas por propiedades, notas, [...] coherentes entre sí: cada una en cuanto propiedad es propiedad de todas las demás, es "propiedad-de". Es lo que con un vocablo tomado de la gramática de las lenguas semíticas, llamo "estado constructo». En el estado constructo los vocablos entre sí, y por

10 Dice Galileo: “...anzi, se i sensi non ci fussero scorta, forse il discorso o l'immaginazione per se stessa non v'arriverebbe già mai." GaliLeI, G., Il Saggiatore, progetto Manuzio, 1997, p. 108 (cursivas mías). En castellano, traducción libre: "[...] digo que siento la necesidad, tan pronto concibo una materia o sustancia corpórea, de concebir junto con ella que está delimitada y figurada de ésta o aquella forma, que en relación a otras es grande o pequeña, que está en este o aquel lugar, en este o aquel tiempo, que se mueve o está quieta, que toca o no toca otro cuerpo, que es una, o pocas o muchas, y ni con gran imaginación puedo separarla de estas condiciones; pero que deba ser blanca o roja, amarga o dulce, sonora o muda, de olor agradable o desagradable, no siento que fuerce a mi mente a tener que aprehenderla acompañada necesariamente de estas condiciones: más bien, sin los sentidos no las hubieran advertido, tal vez el discurso [la razón] o la imaginación por sí mismas no lo hubieran advertido jamás".

11 Zubiri, X., Sobre la Esencia, Alianza, Madrid, 2008, p. 87. 
tanto lo por ellos designado, constituyen formalmente una unidad intrinseca propia. Y esta unidad del estado constructo es lo que yo llamo sistema ${ }^{12}$.

La sustantividad da cuenta de un modo de constitución de las cosas, más concreto en lo efectivo, más general en lo teórico. La sustantividad se da de manera primera; se da al

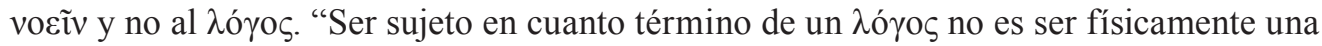
realidad subjetual en cuanto realidad. No es lo mismo ser sujeto de atribución que poseer lo atribuido como propiedad física de un sujeto"13. La constitución de la cosa que la hace ser precisamente esta cosa es primera (prioridad de rango, dice Zubiri), y en ella la totalidad de sus propiedades están puestas unas respecto de otras, sin anterioridad ninguna. Las cosas aparecen primeramente como cosas constituidas en su unidad, sin escisión alguna entre su parecer y su ser, entre la aditividad de sus accidentes y su sustrato sustancial; aparecen constituidas de manera plena. "La sustantividad expresa la plenitud de autonomía entitativa"14. No se trata de la consecución de accidentes respecto de sustancia, sino de la constitución de la totalidad de las notas de la cosa. Esto es: las cosas aparecen como sistemas, y no como elementos aislados inocuos entre sí ni tampoco como errantes accidentes orbitando en torno a un foco sustancial.

Cuando se estudia el organismo de un ser vivo, no hay, en sentido absoluto, un elemento del cual todo lo demás dependa, tan fundamental el cerebro como el estómago, por ejemplo en un animal, pues sin uno el otro no podría hacer lo suyo, en virtud de esto se llama, justamente, organismo. La sustancialidad es el resultado de un proceso racional, del $\lambda$ ó $\gamma$ os, que dé cuenta de alguna realidad ulterior a lo primeramente dado en esta cosa

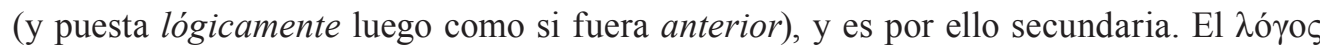
distribuye o despliega la cosa en sujetos y predicados que conforman una proposición, proposición ésta proyectada luego a la realidad como sustancia y accidente. Es así como la sustancia o sustancialidad podrá ser todo lo real e independiente que se quiera, pero es secundaria ${ }^{15}$. Por otro lado, el voeĩv (inteligir) palpa la cosa presente, simple y sistemática, donde no hay diferencia entre el ser y el aparecer. Nótese, sin embargo, que -bien entendido- no se trata del vetusto esse est percipi ${ }^{16}$. La cosa es esta cosa precisamente por ser un

12 Zubiri, X., "Reflexiones teológicas sobre la Eucaristía", Estudios Escolásticos, Nos. 216-217, Vol. 56, EneroJunio, 1981, pp. 41-59, p. 44.

13 ZuBiri, X., op cit., $p 86$

14 Ibid., p. 87.

15 ZuBiRi, X., "Reflexiones teológicas sobre la Eucaristía", op. cit., p. 45: "Radical y formalmente, lo real no es sustancialidad, sino sustantividad".

16 Aunque Zubiri no hablaría ni de "apariciones" ni de "existente", a este respecto me parece que en las primeras páginas de L'être et le néant, con la fenomenología de fondo, Sartre ha sido preclaro: "Les apparitions qui manifestent l'existant ne sont ni intérieures ni extérieures : elles se valent toutes, elles renvoient toutes à d'autres apparitions et aucune d'elles n'est privilégiée. La force, par exemple, n'est pas un conatus métaphysique et d'espèce inconnue qui se masquerait derrière ses effets (accélérations, déviations, etc.): elle est l'ensemble de ces effets. Pareillement le courant électrique n'a pas d'envers secret: il n'est rien que l'ensemble des actions physico-chimiques (électrolyses, incandescence d'un filament de carbone, déplacement de l'aiguille du galvanomètre, etc.) qui le manifestent. Aucune de ces actions ne suffit à le révéler. Mais elle n'indique rien qui soit derrière elle: elle indique elle-même et la série totale. Il s'ensuit, évidemment, que le dualisme de 
sistema complejo constituido por la totalidad de sus notas. El color de esta hoja de papel se presenta como parte constitutiva de la sustantividad de esta hoja de papel; aun cuando, quizá, lo substancial sea su celulosa y no las longitudes de las ondas electromagnéticas que rebotan en ella, éstas como consecuentes a aquélla. Pero sea como sea esta sustancialidad, esta hoja ya presente lo es tanto por su celulosa como por su coloridad. Entendiendo la sustantividad como un sistema de notas que precisa la concretitud de las cosas, la hoja (a)parece blanca porque es blanca, y sólo porque esto es verdadero, patentemente verdadero $(\dot{\alpha} \lambda \dot{\eta} \theta \varepsilon 1 \alpha)^{17}$, es que luego puede volverse a ello con el $\lambda$ ó $\gamma \circ \varsigma$ y desplegar la realidad presentada de manera simple y de antemano. Diego Gracia ha dicho que "si el acto de darme cuenta de que el bastón parcialmente sumergido en el agua está roto no me otorgara algún tipo de saber cierto e indubitable acerca de la cosa, ¿cómo podría yo llegar algún día a deducir las leyes de la refracción?"18. La sustantividad nos muestra la cosa constitutivamente como una unidad integralmente real, y no consecuentemente como habiendo algo en ella más real que lo otro ${ }^{19}$.

Zubiri toma de la sustancia aristotélica el momento de estar presente ( $\tau$ ò ôv), de de-

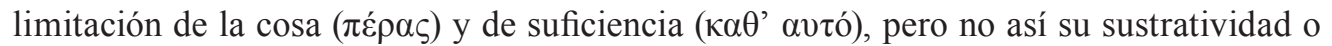

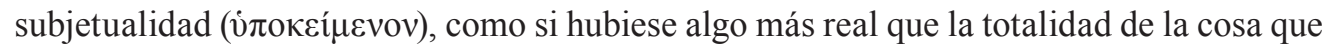
la hace ser, precisamente, esta cosa. Este esta es un deíctico que nos habla de la unidad o delimitación, de la suficiencia o ser por sí, y de su estar aquí ya presente. Las cosas son tales, no tanto por una realidad mayor implícita en ellas, cuanto por el modo como todas sus notas (o "propiedades") quedan estructuradas para constituirlas. La sustantividad nos dice que las cosas son tales por la estructura del todo, en vez que por el enseñoramiento de una de sus partes. Así, por ejemplo, una molécula de agua es tal por estructurarse de dos átomos de hidrógeno y uno de oxígeno $\left(\mathrm{H}_{2} \mathrm{O}\right)$, y sólo es tal por dicha estructura, ningún elemento suyo es más real ni anterior que el resto de la estructura. Antes de ello sólo hay hidrógeno y oxígeno, dos elementos "hidrogenales" y uno "oxigenal" por aparte, pero no agua. El modo de organización es fundamental, pues baste tener en dicha estructura un elemento de más, por ejemplo de oxígeno $\left(\mathrm{H}_{2} \mathrm{O}_{2}\right)$, para dejar de tener agua y tener entonces peróxido de hidrógeno (agua oxigenada). Cualquiera que encuentre irrelevante la estructura, tome un sorbo de $\mathrm{H}_{2} \mathrm{O}_{2}$ en vez de uno de $\mathrm{H}_{2} \mathrm{O}$ y sufrirá, literalmente, las consecuencias. Dice Zubiri:

l'être et du paraître ne saurait plus trouver droit de cité en philosophie.” SARTRE, J.-P., L'Être et le Néant. Essai d'ontologie phénoménologique, Gallimard, Paris, 1943, p. 11.

17 Nótese que $\dot{\alpha} \lambda \hat{\eta} \theta \varepsilon 1 \alpha$ no quiere decir algo como "des-velar", sino más bien "sin-velos". No es lo mismo des- que sin-, pues lo primero es una acción que implica que en efecto hay velos, y que éstos deben ser descorridos; lo segundo, por su parte, quiere decir que efectivamente no hay velo alguno (y, por lo tanto, no hay que descorrer nada).

18 Gracia-Guillén, D., "Actualidad de Zubiri: La Filosofía como Profesión de Verdad", en: Tellechea Idígoras, J.I. (Ed.), Zubiri (1898-1983), Departamento de Cultura del Gobierno Vasco, Vitoria, 1984, p. 90.

19 Zubiri, X., "El hombre, realidad personal", Revista de Occidente, 1, 1963, p. 21: "La sustancialidad sólo es un tipo de sustantividad: la sustantividad que algo posee para que todo lo demás se apoye en él en orden a la existencia. Pero no es la única sustantividad posible. Sustantividad es la suficiencia de un grupo de notas para constituir algo propio; es la suficiencia del orden constitucional." 
[La sustantividad] funcional no es forzosamente el resultado de una combinación de sustancias que produjera una sustancia nueva. Tampoco es un mero agregado de sustancias, porque en tal caso sólo tendríamos funciones aditivas. Es un acoplamiento de sustancias tal que todas ellas se codeterminan mutuamente. Y esto es lo que hemos llamado estructura. La sustantividad está determinada no siempre ni formalmente por sustancias, sino por estructura, y consiste en una unidad coherencial primaria. Esta estructura es la esencia de la sustantividad en cuestión. La suprema forma de unidad metafísica de lo real, no es la unidad de sustancialidad, sino la unidad de sustantividad, la unidad estructural ${ }^{20}$.

La sustancia es la que se separa de la cosa misma como siendo lo más real de la cosa, sustrativamente, sin lo cual no habría tal; la sustantividad, por su parte, es la cosa ya presente, con la que tropiezo, delimitada y suficiente, constituida por su estructura, toda ella. Esto es justamente una constelación de notas que hacen de la cosa una cosa constructa. La sustantividad tiene que ver con la estructura ${ }^{21}$ de algo, con su organización interna que lo hace ser precisamente un algo, ese algo coherente por sí; con una realidad que, de suyo, se articula en relación consigo misma y en relación con lo otro precisamente para ser real y uno. Tal realidad es una y está sistemáticamente organizada. No es una suma de propiedades (o notas), sino la unidad dinámica y estructural que concretiza la especificidad de la cosa. Pongamos un caso: la imposibilidad de medir a una y con la misma precisión el momento y la posición de una "partícula" subatómica muestra que al medir hay que romper: la perturbación del sistema, el colapso de la función de onda, formalmente un rompimiento. Físicamente hemos perturbado el sistema físico. Pero filosóficamente, lo que ha ocurrido es que la sustantividad de dicho fenómeno cuántico ha sido desarticulada en sus propiedades, perdiendo, así, su unidad constitucional ${ }^{22}$. El sistema físico, aun cuando pueda conservar sustancialidad, ha perdido esa sustantividad al haber discernido el momento o la velocidad por separado, siendo así que el sistema físico no sea ya más el mismo: esto es rigurosamente el significado filosófico de la perturbación. En este sentido se ha transsustantivado $^{23}$. Ha ocurrido una transformación de la sustantividad, de su estructura. No se trata ya de sustancialidad alguna como realidad primera. Zubiri dice:

El cloro y el hidrógeno son sustancias, y lo es asimismo el ácido clorhídrico resultante de su combinación, y es una sustancia distinta de las componentes por hallarse dotada de propiedades diferentes a las de éstas. Pero en esta idea [...] entran indiscernidamente dos cosas distintas: la sustancialidad y la sustantividad. [...]

[A]mbos conceptos son perfectamente distintos. La sustancialidad sólo es un tipo de sustantividad: la sustantividad que algo posee para que todo lo demás se apoye en él en orden a la existencia. Pero no es la única sustantividad posible. Sustantividad es la

20 Idem

21 Aquí estoy usando "constructo" y "estructura" sin mucho rigor distintivo. Formalmente son diferentes, pero ahora no viene a cuento detenernos en este detalle que, en otros ámbitos, sería crucial.

22 ZuBiri, X., "Reflexiones teológicas sobre la Eucaristía", op. cit. p. 45: "La transformación de la sustantividad consiste en que el sistema de propiedades pierde su unidad constitucional".

23 Por una trans-actualización en la medición.

24 ZuBiri, X., "El hombre, realidad personal", op. cit., pp. 21-23. 
suficiencia de un grupo de notas para constituir algo propio; es la suficiencia del orden constitucional $^{24}$.

Y también:

Así, la glucosa en un frasco es algo que en la metafísica clásica se llamaba sustancial, pero a la vez es algo sustantivo. En cambio, ingerida en un organismo (prescindiendo de las alteraciones metabólicas), a pesar de conservar integras su presunta sustancia y sus propiedades, sin embargo ha perdido su sustantividad. La sustantividad la tiene solamente el organismo entero: sólo el organismo es el sistema clausurado y total. Por ello la sustancia misma de la glucosa es en el organismo perfectamente insustantiva. Lo radical y primario de las cosas no es, pues, sustancialidad, sino sustantividad. Y la transformación de la sustantividad no es ni remotamente transformación en la sustancialidad: no es transmutación de realidades. La transformación de la sustantividad consiste en que el sistema de propiedades pierde su unidad constitucional ${ }^{25}$.

Si bien el pensamiento moderno abstrae todo cuanto hace que una cosa sea esa cosa, como creía Galileo, a excepción de su realidad primaria precomprendiendo lo que debería ser esa realidad primaria, -lo cual venía desde el pensamiento medieval-, ocurre que, en efecto, se trata más bien de que no tenemos motivos inamovibles para creer que lo sustancial sea más real que el resto de los componentes constitutivos de la cosa. ¿Por qué no podrían ser todos los momentos de la cosa igualmente reales para la cosa misma? A fin de cuentas, ni la contigüidad, ni la secuencialidad, ni la extensión, etc., podrían presumirse como más fundamentales que la cosa misma sin una cosa sustantiva que pueda ser contigua, consecuente, extensa, etc.

\section{Horizontes de precomprensión}

Fundamentalmente un horizonte de precomprensión es el punto de partida desde el cual uno comprende, enjuicia y conceptualiza aquello que es objeto de sus comprensiones, enjuiciamientos y conceptos ${ }^{26}$. Este punto de partida suele ser subrepticio, no es notorio pues está implícito antes de las propias comprensiones, enjuiciamientos, etc. Es el conjunto de presupuestos, precomprensiones, etc., desde el cual uno se lanza a la realidad ${ }^{27}$. Así, por ejemplo, si uno toma un martillo, precomprende que debe ser usado para martillar, y dicha precomprensión va implícita antes, incluso, de siquiera tomar el martillo. Digamos -por usar una analogía musical- que un horizonte es la clave desde la cual se interpreta la obra de la comprensión.

25 Zubiri,X., "Reflexiones teológicas sobre la Eucaristía", op. cit., p. 45.

26 A esto Heidegger llamó Verweisung, (vid. Sein und Zeit, § 17) y Bezogenseins (vid, Ontologie Hermeneutik der Faktizität, capítulo 4). Gadamer le llamará abiertamente Vorverständnis.

27 Seguramente la aprehensión primordial de realidad esté exenta de estos horizontes. Creo que Zubiri así lo pensaría, así lo pienso yo en lo personal; pero es un tema que amerita filosofarse aparte. 
Pues bien, Xavier Zubiri ha encontrado que en la historia de Occidente ha habido dos grandes horizontes desde los cuales se ha comprendido la realidad y los ha llamado $a$ ) el horizonte de la movilidad y b) el horizonte de la nihilidad. El primero es el horizonte nacido con la filosofía griega y muerto también con ella; el segundo es el horizonte nacido con el cristianismo y que culmina en Hegel, aunque dejando secuelas incluso hasta Husserl y Heidegger $^{28}$.

a) Para los griegos, la realidad está dada, no se duda de que pueda o no estar. Es lo que se muestra cuando en la Física Aristóteles dice que es ridículo querer demostrar la existencia de la naturaleza ${ }^{29}$, lo que se muestra con el mismo concepto de $\varphi v ́ \sigma ı \varsigma$ y la constante

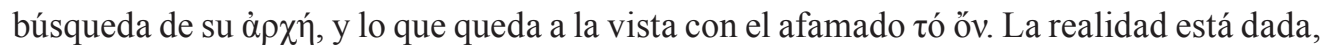
y la pregunta fundamental no va tanto por el lado de si debería o no estar dada sino por cómo es que está ya dada. Es verdad, la realidad ahí está, pero está moviéndose. ¿Cómo puede entonces estar moviéndose sin dejar de estar? Si siempre está, ¿cómo es que está

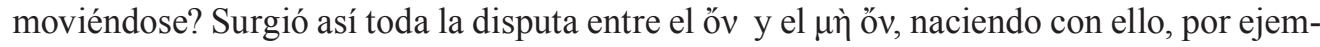

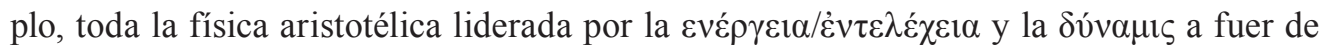
explicar el movimiento. No sólo Aristóteles, sino también Platón pensaba lo propio; bien es sabido que el único intento de Platón por hacer una física está en el Timeo, mostrando que una de las condiciones para lo estrictamente físico, como lo es el tiempo, no es más que una copia imperfecta de la eternidad ${ }^{30}$. Sus predecesores hicieron lo respectivo al no

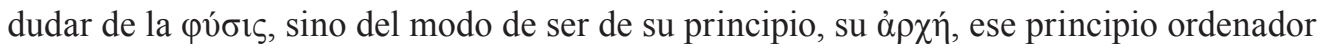
que regula los cambios físicos y que permanece sin cambiar a pesar de generar el cambio. Incluso los eléatas partirán de lo mismo, si bien para ellos el movimiento es aparente, ni duda cabe que hay movimiento -a pesar de que lo más real no se mueva. Quizá esté demás decir que la misma púఠıৎ significa surgir, es decir, brotar, emerger, cambiar. Así pues, no se duda en el horizonte griego de la realidad, sino de cómo podía darse en movimiento. La pregunta fundamental en este horizonte es “¿por qué lo que siempre está, cambia?”. Desde este horizonte se precomprende la estancia de la realidad y su movilidad, y desde aquí se comprende el resto. Este es el horizonte de la movilidad.

28 Zubiri, X., Los problemas fundamentales de la metafísica occidental, op. cit., p. 35: "El mundo griego ha visto esencialmente la idea del ens, la idea del ǒv, desde el horizonte de la movilidad. Si nos trasladamos al mundo medieval, nos encontramos con algo totalmente distinto. Lo primero que piensa el medieval es por qué hay cosas en lugar de que no haya nada. Es curioso que esta pregunta [...] está inscrita dentro del horizonte de la nihilidad, que es el horizonte de la Creación. La idea de la nada no cruzó jamás por la mente de un griego. Para la mente griega, Dios, el $\theta \varepsilon$ ć, no ha hecho el mundo, ni siquiera en Aristóteles; el mundo está naturalmente ahí. En cambio, para un medieval, el mundo empieza por haber llegado a tener realidad. Por consiguiente, todo el problema del ser se inscribe dentro del problema de la nada y de su nihilidad. Y esto ha seguido de una manera muy pertinaz hasta nuestros días".

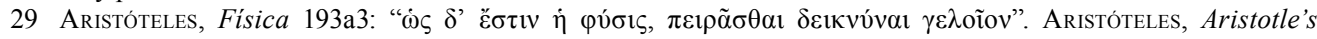
Physics, trad. de W.D. Ross, Clarendon Press, Oxford, 1936.

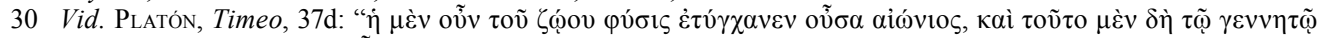

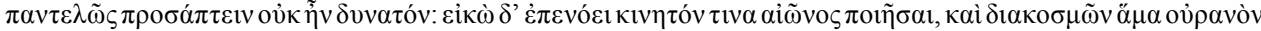

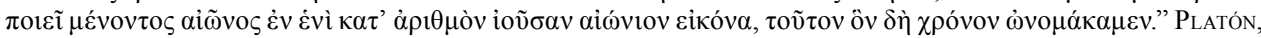
Platonis Opera, trad. de John Burnet, Oxford University Press, London, 1902./ "Pero dado que la naturaleza del mundo ideal es sempiterna y esta cualidad no se le puede otorgar completamente a lo generado, procuró realizar una cierta imagen móvil de la eternidad y, al ordenar el cielo, hizo de la eternidad que permanece siempre en un 
b) Otro es el caso del horizonte de la nihilidad. Este horizonte irrumpe en el anterior con la llegada a Occidente del judeo-cristianismo. Aquí comienza a haber un interés particular por "el ser". El griego no se ocupaba del ser, sino de lo que está; y es que no podría ocuparse del ser porque en su horizonte no está precomprendido, en modo alguno, su contraparte, la nada. Para el griego el mundo ha estado desde siempre y para siempre, y los dioses responden a ello. Pero para el cristiano el mundo no está dado sino que viene dado, viene dado por Dios. Y lo ha dado desde la nada (ex nihilo); cabe hacer mención que esta expresión -originaria de Tertuliano- no es siquiera bíblica, no aparece en el hebreo de la Tanaj, sino tan sólo en una versión poco clara, en lengua griega, del deuterocanónico Macabeos (II, 7, 28), hablando de una creación «desde las cosas que no son/están»

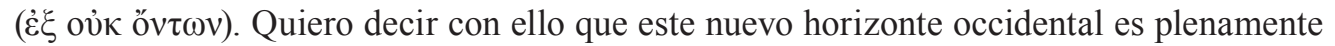
otro. Desde este otro horizonte, se piensa en la posibilidad de que este mundo pudiera ser otro que el que es, es decir, se posibilita la posibilidad misma de los mundos posibles, así como el que el estado de cosas pudiera ser diferente. Este horizonte pregunta no tanto por el cambio y la movilidad de lo dado, sino ahora lo hace por la propia aparición de lo dado, por su quid. En este, la pregunta deja de ser "¿por qué lo que siempre está, cambia?” y deviene en "¿por qué es el ser y no más bien la nada?" prende al mundo como creatura, es decir, como contingente, y desde ahí se comprende al resto.

Pero nos interesa aquí el advenimiento de la ciencia en el cauce de los horizontes. La ciencia moderna, como hoy la conocemos, nace en el horizonte de la nihilidad. La Modernidad toda queda imbuida en él; ¿acaso su padre, Descartes, no retoma a San Agustín en la vuelta a uno mismo para conocer las cosas? ${ }^{32}$ El horizonte de la nihilidad no trata de creencias teológicas, sino de precomprensiones en la resolución fáctica de la realidad, y ahí quedan los padres de la ciencia. Justo es mencionar que el matemático Cauchy, teórico de las funciones continuas y creador de la definición formal de límite, llegó a decir "Yo

punto una imagen eterna que marchaba según el número, eso que llamamos tiempo." Platón, Timeo, Diálogos VI, trad. de María Ángeles Durán y Francisco Lisi, Gredos, Madrid, 2008, p. 182.

31 Recordemos la gran lucha de Leibniz por entender por qué hay algo (quelque chose, lit. cualquier cosa) y no mejor nada (no La Nada, sino nada -Leibniz escribe rien y no néant): "la première question qu'on a droit de faire sera: pourquoi il y a plutôt quelque chose que rien? Carle rien est plus simple et plus facile que quelque chose. De plus, supposé que des choses doivent exister, il faut qu'on puisse rendre raison pourquoi elles doivent exister ainsi, et non autrement". LeiBniz, G., Principes de la nature et de la grâce fondé en raison. Disponible en : http://www.maat.it/livello2/Leibniz-Principes\%20de\%201a\%20nature.html, consultado el 11 de marzo de 2013, Párrafo 7. Esta pregunta, es cierto, no está hecha por el ser, pero sí por la aparición. Además, la interpretación absolutamente entificada (pues ya no habla de "cualquier cosa" sino del "ente" [Seiendes] ni de nada como rien sino como La Nada [no nichts sino Nichts]) de Heidegger al respecto, diciendo que una pregunta tal es fundamental: “Warum ist überhaupt Seiendes und nicht vielmehr Nichts?” HeIdegGer, M., Was ist Metaphysik?, Friedrich Cohen, Bonn, 1931, p. 27.

32 Decía San Agustín: "Noli foras ire, in te ipsum redi, in interiore homine habitat veritas, et si tuam naturam mutabilem inveneris, trascende et te ipsum." (De Vera Religione, XXXIX). Si el nacimiento de la modernidad se realiza con Descartes, baste decir que éste viene retomando una filosofía y un modo de filosofar muy agustino; volver a sí mismo e, incluso, meditar es algo que Agustín inaugura en su afamado si fallor [ergo] sum y en sus Confesiones. Para las influencias medievales en el padre de la Modernidad, vid. GiLson, É., Études sur le rôle de la pensée médiévale dans la formation du système cartésien, Vrin, Paris, 1930. 
soy cristiano, es decir, yo creo en la divinidad de Jesucristo, con Tycho-Brahe, Copérnico, Descartes, Newton, Fermât, Leibniz, Pascal, Grimaldi, Euler, Guldin, Boscowich, Gerdil, con todos los grandes astrónomos, todos los grandes físicos, todos los grandes matemáticos de los siglos pasados"33. El horizonte da cuenta de que previa a sus disertaciones científicas, está precomprendida la realidad desde la nihilidad, esto es, de que las cosas son contingentes y pueden conocerse a partir de lo que no son, y las leyes que van encontrándose son las razones del porqué (y/o cómo) haya algo en vez de nada.

En este horizonte, pues, el conocimiento de las cosas puede ser sustituido por el conocimiento del sujeto que conoce las cosas, o si se quiere: sustituir la realidad por un modelo ideal. El pensamiento moderno presupone una creencia acrítica de una figura dada de la racionalidad, a partir de la cual se cree conocer más la realidad alejándose de ella, tendiendo hacia su idealización. Hay un alejamiento de la realidad en pos de un acercamiento a la razón. Nótese la máxima hegeliana que mienta Was vernünftig ist, das ist wirklich. Was wirklich ist, das ist vernünftig ("lo que racional es, eso es real; lo que real es, eso es racional”). El sujeto impone las condiciones de posibilidad de cognición de la cosa, débilmente hablando; en sentido fuerte: el sujeto impone las condiciones de posibilidad de existencia de la cosa. Lo conocido es subsumido enteramente (o quasi) en el cognoscente. Veremos más adelante como este "estar subsumido" no es sólo un modo de hablar. En términos de la segunda gran metáfora orteguiana: la naturaleza es un pedazo del sujeto, en tanto que contenida en su pensamiento, en tanto que posible sólo como para él. La ciencia, nacida en el horizonte de la nihilidad, resulta idealista anteponiendo la razón del sujeto a la propia constitución de lo real, el científico es tal en la medida en que modela; como si hubiese un modelo racional (instituido racionalmente) al que la realidad deba seguir o, justamente, amoldarse.

Decía entonces que la ciencia nace en el horizonte de la nihilidad, es decir, en el horizonte donde se posibilita lo que las cosas no son, que las cosas no sean y, con ello, en donde es viable conocer lo que es mediante lo que no es. Con el modelo ideal de lo real, se conoce lo que sí es con lo que no es. Conocer la realidad conociendo la idealidad.

Hay que decir, por otro lado, que la Modernidad (y pre-Modernidad) ha visto a la conciencia como un contenedor al cual le llegan contenidos. Es a esto a lo que nos referíamos antes cuando decíamos que lo conocido se subsume en el cognoscente. A veces se le ha visto como un contenedor con forma (Kant), pero, a veces también sin forma (Locke), sea como sea, la verdad es que se le ha visto como contenedor. El mundo, por su parte, es los

33 La cita continúa diciendo: "Yo soy también católico como la mayor parte de ellos; y, si se me pregunta la razón, yo la daré con mucho gusto. Se vería que mis convicciones son el resultado, no de prejuicios de nacimiento, sino de un examen profundo". Citado por Rodríguez Salinas, B. - De María, J.L., "Cauchy", Historia de la Matemática en el siglo XIX, (2 ${ }^{\mathrm{a}}$ parte). Curso de conferencias desarrollado entre Febrero y Abril de 1993, pp. 79-111. Disponible en: http://dmle.cindoc.csic.es/pdf/HISTORIADELAMATEMATICA_1994_00_00_04.pdf. Consultado el 11 de marzo de 2013. 
contenidos que por tales o cuales motivos terminan en aquel contenedor. Para quienes creen que el contenedor tiene forma, los contenidos de la conciencia adoptan la forma de la misma (al modo como, análogamente, lo hace un fluido): el mundo queda subjetivado, es el idealismo; para quienes no lo creen, el contenedor es una tabula rasa que adopta formalidad según la impronta que dejan sus contenidos: el sujeto queda mundanizado, es el empirismo. Empirismo e idealismo son, en bruto, siameses. Sea como fuere, la conciencia es un recipiente que recibe al mundo. El pensamiento occidental moderno, con su ciencia germinal, está inscrito dentro del horizonte de la nihilidad.

Históricamente, pues, acaecen ambos horizontes. Ahora bien, ¿qué hay con el concepto de sustancia? En ambos horizontes la búsqueda de comprensión se ve encaminada a la luz de la sustancia. En el de la movilidad, lo que cambia no es la sustancia; la sustancia es justamente aquello más real que, por ser tal, no cambia. En el de la nihilidad, la sustancia suma no ha sido creada, sino que es justamente la creadora (Ipsum Esse per se subsistens). En este segundo horizonte nace la ciencia moderna. Y si bien su interés no está en esa suma sustancia (pues no requiere de tal "hipótesis" divina, como lo dijera Laplace), sí lo está en aquello que dicha sustancia ha creado a su semejanza: las sustancias perennes del mundo finito, que pueden hallarse, por ejemplo, a la luz de los conceptos de ley y determinismo. Las cosas perennes, no sus contingencias, son sustancias que obedecen siempre a las leyes naturales. Es así como, por ejemplo, es posible en la mecánica clásica conocer toda la trayectoria de cualquier proyectil si de él determinamos la posición y la velocidad. La posición y la velocidad son, para el caso, las cantidades matemáticas que determinan la sustancialidad del proyectil -por decirlo así-, éste tiene (o cobra) realidad física si es viable determinar dichas cantidades: con la posición y la velocidad se conserva la sustancialidad del proyectil, misma que permanece tanto atrás en el tiempo como adelante (determinismo) $)^{34}$.

Hemos de recordar en este punto que si la ciencia moderna nació fue en buena medida por la lucha anti-aristotélica que se tuvo entonces de cara a sus explicaciones cualitativas del mundo físico ${ }^{35}$. Esto, por otro lado, no significó la renuncia a la sustancia, sino la cuantificación de la misma; la sustancia sigue subrepticiamente. Estando Aristóteles en la cumbre de la época histórica del horizonte de la movilidad, fue fácil que sus conceptos se filtraran, igualmente de manera histórica, al siguiente horizonte.

34 Esta noción ha traído vicios en la ciencia contemporánea pues, como "gracias a" posición y momento las cosas "cobran" realidad según la mecánica clásica -ya que de otro modo no podríamos saber de ellas y, sin saberlas, "cómo decir que son reales"-, entonces 1) o el principio de indeterminación de Heisenberg está equivocado (lo que tuvo que rechazarse no de buena gana, sino porque la potencia operativa del mismo obligaba a ello) o bien 2) aquello que se mide en Mecánica Cuántica no es (tan) real, dejando en ascuas a quienes preguntamos por el sentido físico de las ecuaciones matemáticas.

35 Galileo se refiere a los aristotélicos con su personaje abiertamente burlón llamado Simplicio. Cfr. Diálogo sobre dos nuevas ciencias. 
Si recordamos lo que Tomás de Aquino dijo, a saber, que si la inteligencia comprendía la sustancia de alguna cosa no habría nada inteligible de ésta que escapara a la facultad humana de la razón (si intellectus humanus alicuius rei substantiam comprehendit nullum intelligibilium illius rei facultatem humanae rationis excedet), entonces entenderemos el fuerte bagaje de esta precomprensión en las siguientes palabras que Laplace escribió en su Essai philosophique sur les probabilités 36: "Una inteligencia que en un momento determinado conociera todas las fuerzas que animan a la naturaleza [...] podría abarcar en una sola fórmula los movimientos de los cuerpos más grandes del universo y los del átomo más ligero; nada le resultaría incierto y tanto el futuro como el pasado estarían presentes ante sus ojos"37. Se trata aquí de conocer, pues, la sustancia del mundo. Una cosa u otra bien pudo haberla dicho Laplace o el Aquinate. Son parecidos, en efecto, porque ambos discursos parten del mismo horizonte de nihilidad que precomprende como fundamental una realidad primaria; para el caso, la sustancia como materia. Aunque el mismo Aris-

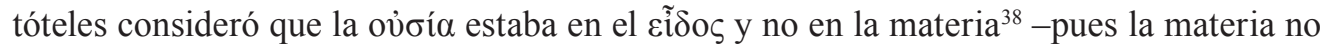

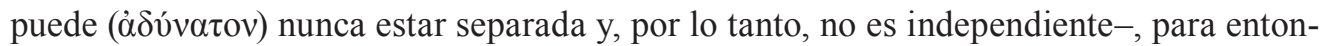
ces la única sustancia que se tomaba por eje era la material. El químico y nobel Wilhelm Ostwald dijo que "la substancia de la Física y la Química del siglo XIX lleva el peculiar nombre de materia. [...] No es del todo fácil determinar unívocamente lo que hoy día se entiende por materia, ya que al intentar dar una definición, resulta que en general se ha presupuesto ya el conocimiento de aquel concepto [...]"39. Por su parte, el mismo Heisen-

36 En lo que sigue de este párrafo, compuesto por lo demás de citas, para facilitar al lector su ritmo citaré en castellano, dejando para las notas al pie los originales.

37 La cita completa es: "Une intelligence qui, pour un instant donné, connaîtrait toutes les forces dont la nature est animée, et la situation respective des êtres qui la composent, si d'ailleurs elle était assez vaste pour soumettre ces données à l'analyse, embrasserait dans la même formule les mouvements des plus grands corps de l'univers et ceux du plus léger atome: rien ne serait incertain pour elle, et l'avenir comme le passé, serait présent à ses yeux". Laplace, Pierre-Simon de, Essai philosophique sur les probabilités, Bachelier, Paris, 1840, p. 4. "Una inteligencia que en un momento determinado conociera todas las fuerzas que animan a la naturaleza, así como la situación respectiva de los seres que la componen, si además fuera lo suficientemente amplia como para someter a análisis tales datos, podría abarcar en una sola fórmula los movimientos de los cuerpos más grandes del universo y los del átomo más ligero; nada le resultaría incierto y tanto el futuro como el pasado estarían presentes ante sus ojos". LAPLACE, Pierre-Simon de, "Ensayo filosófico sobre las probabilidades", en: HaWKING, S. (Ed.), Dios creó los números, Crítica, Barcelona, 2005, p. 362.

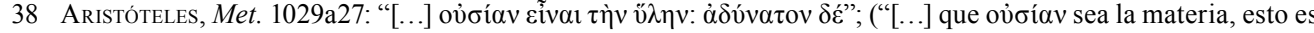
imposible").

39 La cita completa es: "Die Substanz der Physik und Chemie des neunzehnten Jahrhunderts führt den besonderen Namen der Materie. Diese ist sozusagen als Verdampfungsrückstand hinterbliebe, nachdem viele von den Substanzen des achtzehnten Jahrhunderts, insbesondere der Wärmestoff, die elektrischen und magnetischen Materien, das Licht und noch manche andere, im Laufe der Zeit ihres Substanzcharakters verlustig gingen und als "Kräfte" ein mehr geistiges Dasein zu füren angewiesen wurden. Was gegenwärtig unter Materie verstanden wird, ist nicht ganz leicht unzweideutig festzustellen; denn versucht man bestimmte Definitionen zu ermitteln, so findet sich, dass meistens die Kenntniss dieses Begriffes bereits vorausgesetzt wird [...]". OsTWALD, W., Vorlesungen über Naturphilosophie, Veit und comp., Leipzig, 1902, p. 148./ "La substancia de la Física y la Química del siglo XIX lleva el peculiar nombre de materia. La materia es por así decir el residuo de una evaporación, lo que ha quedado luego que muchas de las substancias del siglo XVIII, especialmente el fluido calórico, las materias eléctrica y magnética, la luz y muchas otras, hubieron perdido en el curso de los tiempos su carácter de substancias y, consideradas como 'fuerzas', hubieron accedido a una forma de existencia más espiritual. No es del todo fácil determinar unívocamente lo que hoy día se entiende por materia, ya que al intentar dar una definición, resulta que en general se ha presupuesto ya el conocimiento de aquel concepto [...]". 
berg habló críticamente de la sustancia material desde la electrodinámica: "en la electrodinámica, lo auténticamente existente no es la materia, sino el campo de fuerzas. Un juego de relaciones entre campos de fuerzas, sin ninguna substancia en que se apoyaran dichas fuerzas, constituía una noción bastante menos comprensible que la noción materialista de la realidad $[\ldots]^{\prime 40}$.

Es claro que de la sustancia está brotando la ciencia moderna, pero ya desde sí misma (con el electromagnetismo en general, la teoría cinética de gases, la termodinámica de procesos irreversibles, etc.) es notoria la insuficiencia de tal noción y, con ello, la necesidad de nuevas nociones a la altura de estas igualmente nuevas exigencias.

\section{La altura de nuestros tiempos: nuestro horizonte}

Hoy en día, sin embargo, estudiamos fenómenos que no respetan lo que podríamos llamar el "Principio de Conservación de la Sustancialidad"; por el modo preciso y fino de su estructuración, éstos no son los mismos antes que después, tanto incluso que no podemos regresar a estados previos desde el estado presente y muchas veces ni predecir los futuros. Hemos comentado anteriormente que la realidad de las cosas está en su estructuración, no en un principio único, por lo que al perturbar su estructuración se perturba, de hecho, su modo de ser real. Coincidiendo en esto con Zubiri, no hay que pensar grandes ejemplos, baste simplemente mencionar -para mostrar esta diferencia entre codeterminación sustantiva y dependencia sustancial- la síntesis llevada a cabo por los aminoácidos para la formación de proteínas; los aminoácidos se estructuran de manera tan precisa y adecuada que la proteína resultante es otra que ellos; no es la adición de aminoácidos, sino algo radicalmente nuevo, una macromolécula propia. No es tan sólo su adición, sino el modo concreto en que se articulan efectivamente, un conjunto de aminoácidos sustanciales no hacen una proteína sustantiva, necesitan de una concreta estructura, al modo como un montón de ladrillos no constituyen un muro. Necesitan una cierta disposición, un cierto orden $^{41}$.

Creer que las realidades tienen en ellas algo más real que todo el resto o que su organización intrínseca es creer en la sustancia, y esto no alcanza a concebir ya la totalidad de objetos propios de la ciencia contemporánea. No podemos seguir buscando lo sustancial y dejar de lado todo cuanto creamos accidental. Los problemas ya no son los de antes ${ }^{42}$.

Ostwald, W., "Lecciones sobre filosofía natural”, en Heisenberg, W., La imagen de la naturaleza en la física actual, Planeta, México, 1993, p. 115.

40 Heisenberg, W., La imagen de la naturaleza en la física actual, op. cit. p. 10. El original se llama Das Naturbild der heutigen Physik, desafortunadamente no disponemos de un ejemplar para citarlo, por lo que me disculpo con el lector al no ofrecerle la posibilidad de hacer su propia traducción/interpretación del texto.

41 En otro lugar he dicho: "Ordo es respectividad de algo con otro, de ahí que en función del algo, lo otro quede ordenado; este estar respecto de es estructura". SierRa-Lechuga, C., "Investigación sobre el espacio: desde el aquí hasta la espaciosidad.", Apuntes Filosóficos, Vol. 22, № 43, año 2013, pp. 148.

42 No quiero decir que la física clásica esté obsoleta, sólo estoy diciendo que sus problemas no son los nuevos 
Cuando clásicamente se habla de un cuerpo, por ejemplo, y de él se obtienen determinadas ecuaciones, se trabaja -en general- no con respecto al cuerpo, sino con respecto al centro de masa, es decir, con respecto a un punto, esto es, con respecto a una idealización ${ }^{43}$ -como antes he dicho. Un punto es intrínsecamente inexistente, no es efectivo, sino matemático ${ }^{44}$, el cuerpo es efectivo, pero para estudiarlo prescindimos de él remitiéndonos a la abstracción. Los péndulos cuya masa es puntual, cuyos hilos no tienen masa, y para los cuales no hay resistencia del aire (piénsese en los osciladores armónicos) son buenos ejemplos. Claro que la abstracción (ả $\alpha \alpha i ́ p \varepsilon \sigma 1 \varsigma)$, como toda vía negativa, requiere prescindir de lo particular en pos de lo general; pero no se trata de negar esto, sino de insistir que es ya inadmisible que eso "general" sea considerado como "lo más real". Esta recurrencia epistemológica de perseguir aquello independiente de lo cual lo demás depende, el sustrato, de perseguir la sustancia, ha sido fructífera en el devenir de la ciencia, ni duda cabe. Pero ha ocurrido y, a mi parecer, cada vez ocurre con más frecuencia en nuestro tiempo, que la ciencia se enfrenta a fenómenos que le resultan inabordables, inoperables, o poco abordables y poco operables, por este ardid epistemológico que ha funcionado sólo dentro de determinados límites. Ostwald ya había caído en la cuenta de la insuficiencia del concepto de sustancia en ciencia y decía que "tenemos dos distintos grupos de razones, de las que unas nos llevan a atenernos a la realidad de las cosas según se nos aparecen, y las otras al abandono de dicha apariencia. [Pero] cada una de las indicadas actitudes encierra insuficiencias, mientras que la combinación de ambas constituye una nueva y suficiente tesitura. Es natural que las insuficiencias aludidas hayan de buscarse mediante una delimitación, en dos opuestos frentes, del concepto de substancia"45.

problemas con que hoy nos encontramos. Sus problemas siguen pudiendo ser resueltos (y así seguirán) con física clásica, pero hay otros que exceden su campo epistémico y a ellos me refiero.

43 Hasta que surgiera la genialidad de un gran hombre de ciencia que ideara una matemática menos reduccionista: Henri Poincaré, uno de los padres de la topología.

44 Que diga que un concepto matemático no existe, significa sólo que no está en el mundo efectivo, pero sí en el conceptual; pasa que a esa "existencia" conceptual no le nombro existencia sino consistencia. He tratado esta diferencia (además de la subsistencia) en varias ocasiones: Sierra-Lechuga, C., “¿Por qué decimos que la Realidad es una y que, además, tiene ventanas distintas?", en Navarro, C.-Chamorro, G. (Eds.), Ciencia y Fe: dos ventanas una realidad, Sociedad Educativa Latinoamericana para Fe y Ciencia, Guatemala, 2013, pp. 23-37. También en: Sierra-Lechuga, C., "Dios y la Realidad Fásica: Aplicación de las distinciones entre la consistencia lógica, la existencia objetual y la subsistencia metafísica.”, Apuntes Filosóficos, Vol. 22, N 42, año 2013, pp. 170-201. Y en: Sierra-Lechuga, C., "Asir gradualmente la realidad: para un principio de correspondencia ontológico-epistemológico", Attualidade Teológica, fasc. 45, año XVII, 2013, pp. 553-571.

45 La cita completa es: "Es sind also zwei Gruppen verschiedener Gründe vorhanden, von denen die eine das Festhalten an der Wirklichkeit der Dinge, wie sie uns erscheinen, die andere das Abgehen von dieser Ansicht unterstützt. Wenn der hier vorhandene Widerspruch sich soll lösen lassen, so wird dazu der Nachweis erforderlich seins, dass bei beiden Ansichten Unvollständigkeiten vorhanden sind, deren Ausfüllung die Vereinigung bewirken wird. Diese Unvollständigkeiten werden natürlich in der beiderseitigen Abgrenzung des Substanzbegriffes zu suchen sein". OstwaLD, W., Vorlesungen über Naturphilosophie, op. cit. p. 148. "De modo que tenemos dos distintos grupos de razones, de las que unas nos llevan a atenernos a la realidad de las cosas según se nos aparecen, y las otras al abandono de dicha apariencia. Para resolver esta contradicción, hay que mostrar que cada una de las indicadas actitudes encierra insuficiencias, mientras que la combinación de ambas constituye una nueva y suficiente tesitura. Es natural que las insuficiencias aludidas hayan de buscarse mediante una delimitación, en dos opuestos frentes, del concepto de substancia." OstwaLd, W., "Lecciones sobre filosofía natural", en: Heisenberg, W., La imagen de la naturaleza en la física actual, op. cit., pp. 114-115. 
Pensemos por ejemplo en los fenómenos subatómicos, o en el concepto de sistema, organismo, incluso célula y demás ejemplos mencionados al inicio de este artículo. Fenómenos como éstos exigen ser estudiados no ya desde un horizonte que precomprenda que debería haber en ellos una realidad más real que todo cuando en ellos ocurre, realidad más real que explica y da cuenta de todo cuanto de ella depende. Estos fenómenos exigen ser estudiados desde otro horizonte, porque están siendo planteados desde afuera de los límites que presuponen una realidad suma y perenne. Escapan, pues, a los horizontes viejos reclamando uno nuevo. A éste horizonte Diego Gracia lo llamó el horizonte de la complejidad $^{46}$. En las estructuras complejas no se trata de buscar una realidad sustancial de la que dependa toda la estructura, como si tuvieran una piedra angular; toda la estructura es real y toda ella tiene manifestaciones propias inexplicables sin la totalidad de la estructura. Ver la totalidad de la estructura como un único fenómeno en vez de como un conglomerado de accidentes dependientes de una sola "parte" es partir desde un nuevo horizonte abierto a las exigencias de los problemas de la ciencia de nuestro tiempo.

¿Por qué es que no puedo medir a la vez la posición y el momento de una partícula subatómica con arbitraria precisión? Esta pregunta se lanza sólo si se precomprende que la sustancia de un fenómeno tal está en su carácter de ser partícula. Las partículas son sustancialmente determinables por su momento y posición. Pero este fenómeno subatómico requiere de otra clave (la clave de interpretación) según la cual esta pregunta resulta ser, a la postre, una pseudo-pregunta o, al menos, una deutero-pregunta. Si se ve al fenómeno como totalidad estructural no nos parecería extraña la ausencia de características de partícula, porque de hecho no esperaríamos que fuese una partícula, o que se comportase como tal; lo mismo si esperamos que se comportase como onda. Es verdad que hoy decimos que para ciertos experimentos el fenómeno acontece como siendo partícula, para otros no; pero ¿cómo se explica este cambio de dirección en la naturaleza? No se explica, y por eso tienen los científicos que recurrir a antropomorfismos como "el electrón decide si...": no, no decide nada, carecemos de conceptos porque seguimos circundando uno que nos limita la visión de cara a esta clase de fenómenos: la sustancia. La totalidad de este fenómeno es total, y siendo el caso, uno debe verla como tal. Es labor filosófica la especulación de nociones útiles en el abordaje de lo real, y es labor filosófica proveer de herramientas teóricas según las cuales el científico tenga de dónde partir para nuevas herramientas matemáticas precisas ${ }^{47}$, una matemática que mire los sistemas rigurosamente como sistemas constituidos por sus propiedades estructurales, todos mayores a la suma de sus partes, y no como efectos consecuentes de un único principio.

46 Conferencia llamada "Nuestra situación intelectual: Zubiri en el horizonte de la complejidad.", dictada por Diego Gracia Guillén (Fundación Xavier Zubiri, España) el martes 31 de agosto de 2010 en el marco del III Congreso Internacional Xavier Zubiri que tuvo lugar en el Salón de Honor de la Pontificia Universidad Católica de Valparaíso, Chile. Disponible en: https://www.youtube.com/watch?v=S7BQMyTdPJA

47 Es verdad que ya se intentan (la matemática fractal, sistemas dinámicos [sistemas de ecuaciones diferenciales], matemática del caos, cómputo numérico, teoría de juegos, variable compleja, etc.), pero según nos dice la experiencia, con un éxito grande -sin duda-, pero no tan grande como se esperaría. 


\section{Conclusión}

Confío en que el filósofo español Xavier Zubiri, quien hubiera estudiado con Einstein y Schrödinger en Berlín, y con Louis de Broglie en París, ha dado en el clavo para el abordaje de las nuevas realidades a las que nos enfrentamos en nuestro tiempo. Nuestra situación intelectual da para más que un mero análisis lógico del lenguaje, y no se trata aquí de distinguir taxonómicamente lo que es sustancia de lo que es sustantividad, se trata de escuchar a la realidad misma de las cosas y ver qué tienen ellas que decirnos, por encima de lo que nuestros modelos canónicos y canonizantes prefieren. Se trata, a la postre, de atenerse modestamente a la realidad de las cosas, de atender más a las cosas de las que queremos saber antes que a nuestras preconcepciones y prejuicios desde los cuales decimos qué queremos saber. Nuestra situación intelectual nos exige ver las cosas en su estructura, como sistemas, como complejos, como realidades respectivas ${ }^{48}$ y no inocuas. Interpretarlas en una nueva clave puede dificultar nuestro acercamiento al ser éste uno nuevo, radicalmente otro que ese que nos mantenía en un nivel considerable de certezas y en un estado confortable, pero aminora la carga cuando la clave resulta ser una luz a la que esas realidades, poco comprensibles desde otro enfoque, son ahora sensibles. No es que la realidad sea translúcida y por lo tanto estemos vedados de verla por principio, pasa que debemos ajustar las longitudes de nuestras radiaciones gnoseológicas hasta alcanzar lo mínimo necesario para que reboten contra su real e intrínseca opacidad. Aunque sea más cómodo afirmar que sólo es cognoscible aquello donde hasta ahora conocemos, no es esto ni verdadero ni laudable. Amicus Plato, sed magis amica veritas, donde Plato significa cualquier cosa que interpele al lector. Ver desde donde no se ha visto o desde donde apenas se ha empezado a ver, sin duda será arduo, pero al final alguien tiene que poner (de: $\theta \dot{\sigma} \sigma ı \varsigma)$ la vista (de: ópó $\omega)$ en ello, es decir, alguien tiene que teorizar ( $\theta \varepsilon \omega \rho i ́ \alpha)$. Quizá no sea la sustantividad la mejor noción para acercarse a las realidades complejas a las que hoy nos enfrentamos, quizá haya otras muchas que ayuden más y mejor, pero es una que atiende honestamente al escudriñamiento de la totalidad de lo real; escudriñamiento frente al cual Platón, hace ya más de 2000 años, confesó haber desfallecido ${ }^{49}$ pero -como enseñara Zubiri- no por ello haberse desalentado ${ }^{50}$ *

48 Zubiri también trató el tema de la respectividad de lo real. Tema de orden metafísico pero que, nuevamente, a mi parecer, puede ser retrotraído al del orden físico (propio de las ciencias).

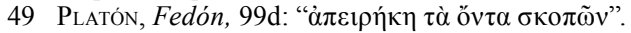

50 Zubiri, X., Los problemas fundamentales de la metafísica occidental, op. cit., p. 121.

*Artículo recibido: 9 de noviembre de 2014. Aceptado: 14 de diciembre de 2014. 


\section{Bibliografía}

Aristóteles, Aristotle’s Physics, trad. de W.D. Ross, Clarendon Press, Oxford, 1936.

\section{4.}

, Aristotle's Metaphysics, trad. de W.D. Ross, Clarendon Press, Oxford,

De Aquino, Tomás, Suma contra los Gentiles, trad. de Carlos Ignacio González, Porrúa, México, 2004.

, Summa contra Gentiles, Typis Ricardi Garroni, Romae, 1928.

Galilei, Galileo, Il Saggiatore, progetto Manuzio, 1997.

Gilson, ÉTIENne, Études sur le rôle de la pensée médiévale dans la formation du système cartésien, Vrin, Paris, 1930.

Gracia-Guillén, Diego, “Actualidad de Zubiri: La Filosofía como Profesión de Verdad”, en: Tellechea Idígoras, J. Ignacio (Ed.), Zubiri (1898-1983), Departamento de Cultura del Gobierno Vasco, Vitoria, 1984.

Heidegger, Martin, Was ist Metaphysik?, Friedrich Cohen, Bonn, 1931.

Heisenberg, Werner, La imagen de la naturaleza en la física actual, Planeta, México, 1993.

Laplace, Pierre-Simon De, "Ensayo filosófico sobre las probabilidades", en Hawking, Stephen (Ed.), Dios creó los números, Crítica, Barcelona, 2005.

1840.

Essai philosophique sur les probabilités, Bachelier, Paris,

Leibniz, GotTfried, Principes de la nature et de la grâce fondé en raison, disponible en: http://www.maat.it/livello2/Leibniz-Principes\%20de\%201a\%20nature.html, consultado el 11 de marzo de 2013.

Ostwald, Wilhelm, "Lecciones sobre filosofía natural”, en: Heisenberg, Werner, La imagen de la naturaleza en la física actual, Planeta, México, 1993.

1902.

, Vorlesungen über Naturphilosophie, Veit und comp., Leipzig, 
Platón, Timeo, Diálogos VI, trad. de María Ángeles Durán y Francisco Lisi, Gredos, Madrid, 2008.

---------, Platonis Opera, trad. de John Burnet, Oxford University Press, London, 1902.

Rodríguez Salinas, Baltasar-De María, José L., "Cauchy", Historia de la Matemática en el siglo XIX, (2 $2^{\mathrm{a}}$ parte). Curso de conferencias desarrollado entre Febrero y Abril de 1993, pp. 79-111. Disponible en: http:// dmle.cindoc.csic.es/ pdf/HISTORIADELAMATEMATICA_1994_00_00_04.pdf. Consultado el 11 de marzo de 2013.

Sierra-Lechuga, Carlos, “¿Por qué decimos que la Realidad es una y que, además, tiene ventanas distintas?", en: Navarro, César-Chamorro, Gonzalo (Eds.), Ciencia y Fe: dos ventanas una realidad, Sociedad Educativa Latinoamericana para Fe y Ciencia, Guatemala, 2013.

"Dios y la Realidad Fásica: Aplicación de las distinciones entre la consistencia lógica, la existencia objetual y la subsistencia metafísica.", Apuntes Filosóficos, Vol. 22, № 42, año 2013, pp. 170-201.

---------------------------, “Investigación sobre el espacio: desde el aquí hasta la espaciosidad.”, Apuntes Filosóficos, Vol. 22, № 43, año 2013, pp. 141-165.

, "Asir gradualmente la realidad: para un principio de correspondencia ontológico-epistemológico", Attualidade Teológica, fasc. 45, año XVII, 2013, pp. 553-571.

ZuBIRI, XAVIER, "El hombre, realidad personal”, Revista de Occidente, 1, 1963.

, "Filosofía y Metafísica,” Cruz y Raya 10, 1935.

-------------, "Reflexiones teológicas sobre la Eucaristía”, Estudios Escolásticos, Nos. 216-217, Vol. 56, Enero-Junio, 1981.

-, Los problemas fundamentales de la metafísica occidental, Alianza, Madrid, 2008.

, Sobre la Esencia, Alianza, Madrid, 2008. 